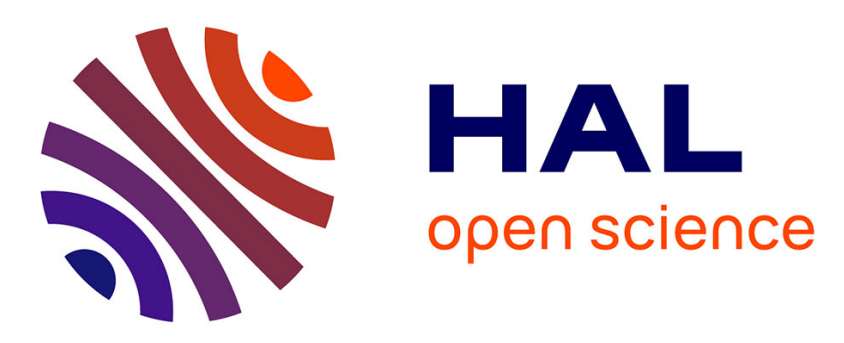

\title{
Mixed-mode debonding approach to evaluate water sensibility in bi-layer composite pavement
}

\author{
Armelle Chabot, Ferhat Hammoum, Manitou Hun
}

\section{To cite this version:}

Armelle Chabot, Ferhat Hammoum, Manitou Hun. Mixed-mode debonding approach to evaluate water sensibility in bi-layer composite pavement. 8th International conference on Mechanisms of Cracking and Debonding in Pavements (MCD2016). Chabot A., Buttlar W.G., Dave E.V., Petit C., Tebaldi G. (Eds), RILEM bookseries, vol. 13, Jun 2016, Nantes, France. pp.613-618, 10.1007/97894-024-0867-6_86. hal-01338327

\section{HAL Id: hal-01338327 https://hal.science/hal-01338327}

Submitted on 28 Jun 2016

HAL is a multi-disciplinary open access archive for the deposit and dissemination of scientific research documents, whether they are published or not. The documents may come from teaching and research institutions in France or abroad, or from public or private research centers.
L'archive ouverte pluridisciplinaire HAL, est destinée au dépôt et à la diffusion de documents scientifiques de niveau recherche, publiés ou non, émanant des établissements d'enseignement et de recherche français ou étrangers, des laboratoires publics ou privés. 


\title{
Mixed-mode debonding approach to evaluate water sensibility in bi-layer composite pavement
}

\author{
Armelle Chabot, Ferhat Hammoum \\ LUNAM Université, Ifsttar, CS4, 44344 Bouguenais Cedex, France, \\ armelle.chabot@ifsttar.fr
}

\section{Manitou Hun}

LBL International, 34 Sothearos Boulevard, Phnom Penh BP 609, Cambodia

\begin{abstract}
In order to evaluate water sensibility on the interfacial properties between layers of composite pavements, a four-point bending (4PB) test on bilayer structure in a water bath is proposed. Using the virtual crack closure technique, the individual strain energy release rates are calculated with a specific model. The debonding driven by Mode I failure is recognized as the main mode. For bilayer specimens made of a cement concrete overlay on bituminous material, the specific test has shown a competition between the different failure mechanisms. A very good bond resistance between layers compared to the fracture tension resistance of the cement concrete layer is observed. In this work, first results of the water effect on the behavior of such a material interface are presented. The final fracture length of the specimens, curves of force-displacements and first digital image correlation results show the influence of water immersion on the debonding failure mode.
\end{abstract}

Keywords four-point bending test, water, debonding, composite pavements.

\section{Introduction}

Composite pavement systems, made of concrete/asphalt and asphalt/concrete structure, show good potential for becoming an interesting rehabilitation option for urban pavements that exhibit structural deterioration (De Larrard et al., 2005). However, due to shrinkage phenomenon of cement materials, the existing vertical crack combined to environmental and traffic loading lead to failures that may develop as delamination between layers (Chabot et al., 2008). Typically, such debonding initiates and propagates under the combined influence of normal and shear stresses (Chabot et al., 2005). The presence of water, whatever its phase is, adds to this complex phenomenon an irreversible damage that cannot be ignored 
(Vandenbossche et al., 2011) (Raab et al., 2012). The damage can be driven with two mechanisms: (a) loss in strength and durability of materials due to the presence of water in the pore of asphalt concrete (b) loss of mechanical behavior of bond between layers. Evaluating the effect of water on the interface behavior is complex. In order to capture this effect on the interface between layers of composite pavements, a four-point bending (4PB) test is applied on bilayer structure in a water bath. Without water, the specific test has shown significant interface debonding in mixed mode (mode I and II) condition (Hun et al., 2012) (Chabot et al., 2013). In this work, results of the effect of the water immersion on the behavior of a cement concrete / asphalt material interface are presented. Final fracture length, curves of force-displacement and digital image correlation (DIC) are used to investigate if the presence of water in the bi-layer specimen influences debonding failure mode during the 4PB test.

\section{Theoretical characterization of the bond during the 4PB test}

Following results stemming from concrete beams strengthened by externally bonded plates, a 4PB test has been adapted for the pair of bituminous and cement concrete materials (Hun et al., 2012). This test has the advantage to investigate the interfacial behavior under mixed mode conditions without using any supports or applying any loads directly on the bituminous material (Figure 1).

(a)

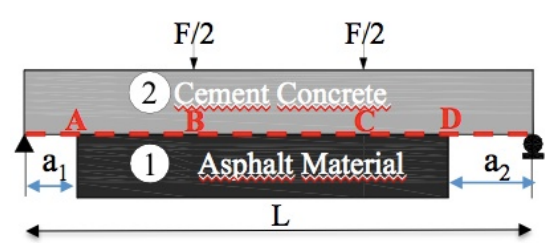

(b)

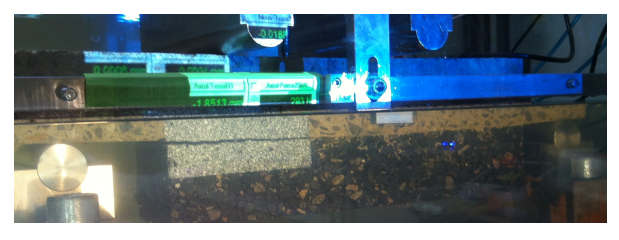

Fig. 1 (a) The four-point bending test configuration; (b) The debonding phenomenon into water

The multi-particle model of multilayer materials (M4) with five kinematic fields per layer is chosen to design and to investigate the debonding results of the 4PB test on bi-layer specimens. The approximations of the so-called M4-5n (n: total number of layers i) offer the advantage of defining the out-of-interface plane normal $v^{i, i+1}$ and shear stresses $\tau^{i, i+1}$ at interface between layers $i$ and $i+1$. As opposed to other classical models, the main interest of this modeling is to yield finite stresses at a free edge or crack tip at the interface point location of two different layers and accelerate the computation process (Chabot, 1997). For crack initiation problems, two delamination criteria in the angle-ply laminates have been proposed (Chabot, 1997) (Caron et al., 2006). The first one is based on the maximum value 
of interface stresses. Using the virtual crack closure technique (VCCT) (Bui, 1978) (Moutou Pitti et al., 2008), the second criterion is based on an analytical calculation of the individual strain energy release rates $\left(\mathrm{G}_{\mathrm{I}}, \mathrm{G}_{\mathrm{II}}, \mathrm{G}_{\mathrm{III}}\right)$. Applied to the $4 \mathrm{~PB}$ test under $2 \mathrm{D}$ plane strain assumptions, the M4-5n solutions are given in a previous work with parametric calculations (Chabot et al., 2013). It indicates that a competition exists between tensile stress at the bottom of the cement concrete in layer 2 (between points B and C) and interface normal and shear stresses (at points $A$ and D) (Figure 1a). In order to obtain the debonding phenomenon between the two layers onto only one side, a non-symmetrical geometry of the specimens is proposed. A higher geometrical value of $a_{2}$ length compared to the $a_{1}$ length one favors delamination on the side $\mathrm{a}_{2}$ first (Figure 1a). For the 4PB test with a debonding crack length 'a" (Figure 1b), the analytical expression of strain energy release rates is given in (Eq. 1) where $\mathrm{b}$ is the width of the beam. $\mathrm{e}^{\mathrm{i}}, \mathrm{E}^{\mathrm{i}}$ and $v^{\mathrm{i}} \mathrm{de}-$ note the thickness, Young's modulus and Poisson's ratio of each layer i respectively. Only $G_{I}$ is a pure quadratic function of the normal interface stress. $G_{I I}$ takes into account the combined terms containing the shear interface stress, shear force $Q_{1}^{i}$ of each layer i.

$G_{T}(a)=G_{I}(a)+G_{I I}(a)$
with $\left\{\begin{aligned} G_{I}(a)= & \frac{1}{2 b} \cdot \frac{13\left(e^{1} E^{2}+e^{2} E^{1}\right)}{35 E^{1} E^{2}}\left(v^{1,2}(a)\right)^{2} \\ G_{I I}(a)= & \frac{1}{2 b} \cdot \frac{4\left(e^{1}\left(1+v^{1}\right) E^{2}+e^{2}\left(1+v^{2}\right) E^{1}\right)}{15 E^{1} E^{2}}\left(\tau^{1,2}(a)\right)^{2} \\ & -\frac{1}{2 b} \cdot\left(\frac{\left(1+v^{1}\right)}{5 E^{1}} Q_{1}^{1}(a)+\frac{\left(1+v^{2}\right)}{5 E^{2}} Q_{1}^{2}(a)\right) \cdot \tau^{1,2}(a)\end{aligned}\right.$

\section{$3 \quad$ Results and discussion}

4PB tests on bi-layer specimens are performed under controlled static conditions $\left(0.7 \mathrm{~mm} / \mathrm{min}, 20^{\circ} \mathrm{C}\right.$ constant temperature). To improve the understanding of the fracture scenario of bi-layer materials of such a 4PB test, Digital Image Correlation (DIC) technics are used (Sutton, 1983) (Figure 2). The largest resolution of the camera is $1388 \times 1038$ pixels at 63 frames per second. In order to control and measure the imposed displacement $\left(\mathrm{U}_{\mathrm{z}}\right)$, a linear variable differential transducer (LVDT) sensor is placed at the mid-span (L/2) on the top of the specimen $\left(\mathrm{z}=\mathrm{e}^{1}+\mathrm{e}^{2}\right)$ (figure 1). The force $(\mathrm{F})$ is recorded directly on the hydraulic testing machines. During the test, to find the correspondence between each image and the loading conditions, the resulting force and the displacement values are inserted in the images (Figure 2). 

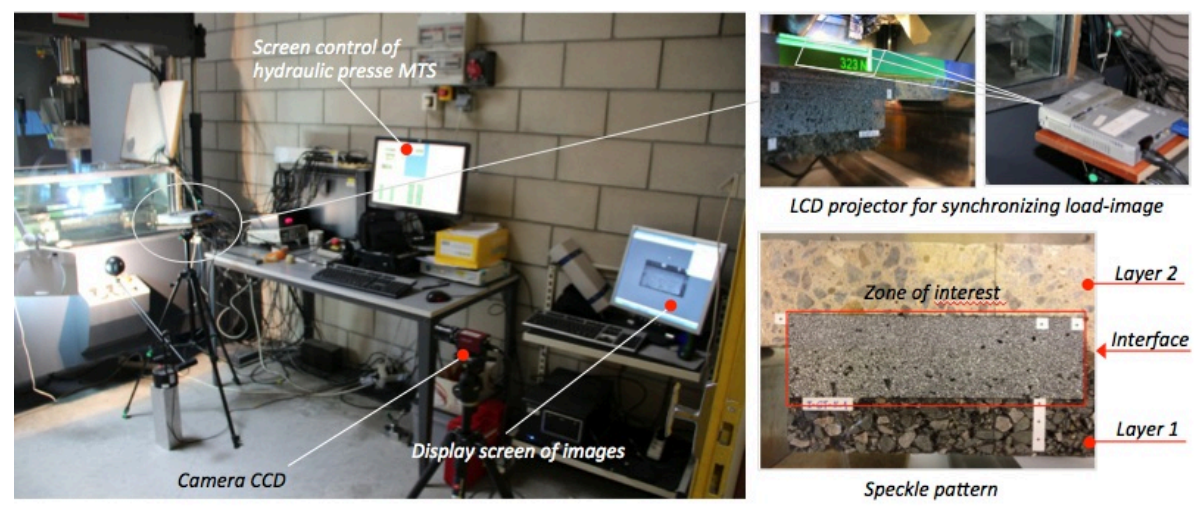

Fig. 2 General description of the immersed 4PB equipment with DIC system

A reference specimen made with an aluminum (Alu) homogeneous layer 2 sticks with epoxy glue, on PVC homogeneous layer $1(\mathrm{~L}=420 \mathrm{~mm} ; \mathrm{b}=125 \mathrm{~mm}$; $\mathrm{a} 1=40 ; \quad \mathrm{a} 2=71 ; \quad \mathrm{e}^{1}=30.6 ; \quad \mathrm{e}^{2}=40.6 \mathrm{~mm} ;$ Young modulus ratio: $\mathrm{E}^{2} / \mathrm{E}^{1} \approx 22.4$; $\left.v^{1}=0.30 ; v^{2}=0.34\right)$ is first tested to validate the M4-5n strain energy release rate results compared to classical ones from the literature. Table 1 shows that the energy release rates of the M4-5n calculus are validated successfully compared to Dundurs's approach (Dundurs, 1969). Mode I is recognized as the main failure mode.

Table 1 M4-5n energy release rate results compared to Dunders ones for an Alu/PVC specimen

\begin{tabular}{lllll}
\hline & Crack length $(\mathrm{mm})$ & $\mathrm{G}_{\mathrm{I}}\left(\mathrm{J} / \mathrm{m}^{2}\right)$ & $\mathrm{G}_{\mathrm{II}}\left(\mathrm{J} / \mathrm{m}^{2}\right)$ & $\mathrm{G}_{\text {Total }}\left(\mathrm{J} / \mathrm{m}^{2}\right)$ \\
\hline Dundurs & \multirow{2}{*}{$70 \pm 1$} & 93 & 35 & 128 \\
M4-5n & & 106 & 21 & 127 \\
\hline
\end{tabular}

As opposed to tests conducted on Alu/PVC specimens, the determination of strain energy release rate seems more complicated for bi-layer specimen made of cement concrete overlay on bituminous material. The competition between the poor tensile resistance of the cement concrete layer and the good bond of such an interface adds complexity to the analysis (Chabot et al., 2013). In order to evaluate the additional effect of water during the debonding process, an aquarium is built. Prior to being tested, the specimens are saturated during two hours in a vacuum box filled of water. The wall glass of the aquarium, with its refraction index identical to the water one, allows using the DIC system (Figure 2). M4-5n calculations indicate that, at a loading force of $F=4.2 \mathrm{kN}$, the tensile stress $\left(\mathrm{R}_{\mathrm{t}}\right)$ at the bottom of the layer 2 made of the cement concrete tested air is supposed to reach its maximum tensile value (around $\mathrm{Rt}=3.46 \mathrm{MPa}$ ) at point $\mathrm{C}$ before point $\mathrm{B}$ in this antisymmetrical specimen geometry case $(L=420 \mathrm{~mm} ; b=100 \mathrm{~mm} ; \mathrm{a} 1=40 ; \mathrm{a} 2=71$; $\mathrm{e}^{1}=\mathrm{e}^{2}=60 \mathrm{~mm} ; \mathrm{E}^{2} / \mathrm{E}^{1} \approx 17.5 ; v^{1}=v^{2}=0.35$ ). Figure 3 resumes only the static $4 \mathrm{~PB}$ results for specimens $\left(\mathrm{I}-\mathrm{PT}-\mathrm{N}^{\circ}\right.$ slab- $\mathrm{N}^{\circ}$ specimen) instrumented with the DIC system. 


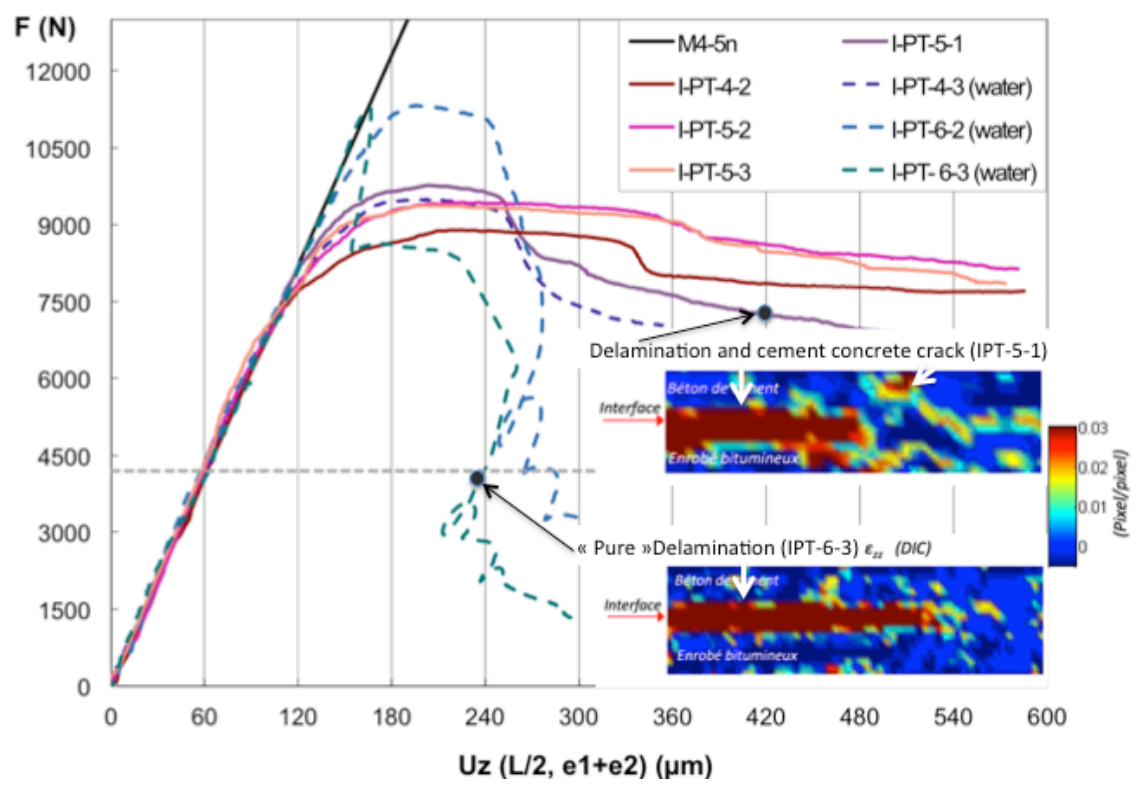

Fig. 3 Curves of force-displacement results of cement concrete/bituminous specimens tested on air and into water with the $4 \mathrm{~PB}$ test $\left(0.7 \mathrm{~mm} / \mathrm{mn}, \mathrm{T}=20^{\circ} \mathrm{C}\right)$

In this experimental work, among the specimens $(4-2 ; 5-2 ; 5-3,5-1)$ tested in air, only the $5-1$ one has failed with an interface-debonding mode between layers. The bi-layer specimens tested into water (4-3; 6-2; 6-3) failed by debonding mode. The corresponding curves of force-displacement show that after the maximum value of the loading force, the force decreases suddenly (Figure 3). The final debonding length of bi-layer specimen (Figure 1b), obtained in this work and a previous one (Chabot et al., 2013), gives $59 \mathrm{~mm}$ for specimens tested in air (calculated from 4 specimens) compared to $97 \mathrm{~mm}$ for specimens tested into water (from 3 specimens). The image analysis confirms that, even if the IPT-5-1 specimen failed with interface debonding mode, a parasite crack is observed in the cement concrete material (Figure 3). On the contrary, for 1PT-6-2 and 1PT-6-3 specimens tested into water, no parasite cracks are observed.

For specimen tested into water, Table 2 indicates first $G$ results. Due to the elastic assumption of the M4-5n and the material considered in that study, these results can be considered as maximum values.

Table 2 Average M4-5n energy release rate results for 1PT-6-2 \& 1PT-6-3

\begin{tabular}{lllll}
\hline & Crack length $(\mathrm{mm})$ & $\mathrm{G}_{\mathrm{I}}\left(\mathrm{J} / \mathrm{m}^{2}\right)$ & $\mathrm{G}_{\mathrm{II}}\left(\mathrm{J} / \mathrm{m}^{2}\right)$ & $\mathrm{G}_{\text {Total }}\left(\mathrm{J} / \mathrm{m}^{2}\right)$ \\
\hline 1PT-6-2\&3 & 16.5 & 155 & 18 & 173 \\
\hline
\end{tabular}

All this preliminary results lead to confirm that water has an effect and favors interface debonding phenomenon in such an adapted 4PB test. 


\section{Conclusion}

In order to investigate under water the mechanical behavior of interface between layers, a 4PB test has been adapted. Using the VCCT and debonding assumptions, individual strain energy release rates are calculated with a specific model. Debonding mode I should be recognized as the main failure mode. On specimens made with a cement concrete overlay on a bituminous material layer, all the results confirms that, in air, the delamination process is in competition with micro cracks at the bottom of the cement concrete layer during the test. On the contrary, water presence seems to favor debonding phenomenon in such a 4PB test. More investigations need to be done with more tests and in comparison to other debonding tests such as those done by (Tchegg et al., 2007) and the different Rilem TCs.

\section{References}

Bui H (1978) Mécanique de la rupture fragile. Ed Masson, Paris.

Caron JF, Diaz Diaz A, Carreira RP, Chabot A, Ehrlacher A. (2006) Multi-particle modeling for the prediction of delamination in multi-layered materials. Comp. Sc. \&Tech., 66(6): 755-765

Chabot A (1997) Analyse des efforts à l'interface entre les couches des matériaux composites à l'aide de Modélisations Multiparticulaires des Matériaux Multicouches (M4). ENPC PhD thesis, (https://tel.archives-ouvertes.fr/tel-00197853/)

Chabot A, Tran QD, Ehrlacher A (2005) A simplified modeling for cracked pavements. Bulletin des Laboratoires des Ponts et Chaussées, ISSN 1269-1496, (258-259): 105-120

Chabot A, Pouteau B, Balay J-M, De Larrard F (2008) FABAC Accelerated Loading Test of Bond between Cement Overlay and Asphalt layers. 6th Rilem Int. Conf. on Cracking in Pavements, June 16-18 2008, Chicago, US. Taylor \& Francis Group Proceedings, 13-23

Chabot A, Hun M, Hammoum F (2013) Mechanical analysis of a mixed mode debonding test for "composite" pavements. Construction and Building Materials, 40: 1076-1087

Dundurs J (1969) Edge-bonded dissimilar orthogonal elastic wedges under normal and shear loading. Transactions of the ASME, Journal of Applied Mechanics, 650-652

Hun M, Chabot A, Hammoum F (2012) A four point bending test for the bonding evaluation of composite pavement. RILEM Bookseries, 4: 51-60, doi: 10.1007/978-94-007-4566-7_6

De Larrard F, Chabot A, Sedran T, Pouteau B, Mathias V (2005) Recent developments in French concrete pavement technology. Global Construction: Ultimate concrete opportunities. Concrete for Transportation Infrastrastructure, 19-26, doi: 10.1680/cfti.34020

Moutou Pitti R, Dubois F, Petit C, N Sauvat, Pop O (2008) A new M-integral parameter for mixed-mode crack growth in orthotropic viscoelastic material. EFM, 75(15): 4450-4465

Raab C, Partl MN, Abd El Halim AO (2012) Effect of moisture on interlayer bonding of asphalt pavements. $7^{\text {th }}$ Int. conf. on Maintenance and Rehabilitation of Pavements and Technological Control, Auckland, New Zealand, August 28-3

Sutton M, Wolters W, Peters W, Ranson W, McNeill S (1983) Determination of displacements using an improved digital correlation method. Image and Vision Computing, 1(3): 133-139

Tschegg EK, Macht J, Jamek M, Stegenberger J., (2007) Mechanical and Fracture-Mechanical Properties of Asphalt-Concrete Interfaces. ACI Materials, 104 (5): 474-480

Vandenbossche J, Barman M, Mu F, Gatti, K (2011) Development of design guide for thin and ultra-thin concrete overlays of existing asphalt pavements. Technical report, University of Pittsburgh, http://www.lrrb.org/media/reports/201125.pdf 